$9-15-1998$

\title{
Electron Transfer Catalysis of The Hydrogenolysis of Acyl Dicarbonyl Cyclopentadienyliron Complexes by Tributyltin Hydride
}

\author{
Christian Amatore \\ Processus d'Activation Moléculaire \\ Mekki Bayachou \\ Cleveland State University, M.BAYACHOU@csuohio.edu \\ Olivier Buriez \\ Processus d'Activation Moléculaire \\ Jean Noel Verpeaux \\ Processus d'Activation Moléculaire
}

Follow this and additional works at: https://engagedscholarship.csuohio.edu/scichem_facpub

Part of the Chemistry Commons

How does access to this work benefit you? Let us know!

\section{Recommended Citation}

Amatore, Christian; Bayachou, Mekki; Buriez, Olivier; and Verpeaux, Jean Noel, "Electron Transfer Catalysis of The Hydrogenolysis of Acyl Dicarbonyl Cyclopentadienyliron Complexes by Tributyltin Hydride" (1998). Chemistry Faculty Publications. 311.

https://engagedscholarship.csuohio.edu/scichem_facpub/311

This Article is brought to you for free and open access by the Chemistry Department at EngagedScholarship@CSU. It has been accepted for inclusion in Chemistry Faculty Publications by an authorized administrator of EngagedScholarship@CSU. For more information, please contact library.es@csuohio.edu. 


\title{
Electron transfer catalysis of the hydrogenolysis of acyl dicarbonyl cyclopentadienyliron complexes by tributyltin hydride
}

\author{
Christian Amatore , Mekki Bayachou, Olivier Buriez, Jean-Noël Verpeaux
}

\section{Introduction}

The reductive cleavage of the metal carbon bond of transition metal acyl compounds is an important reaction, which occurs as the final step of many catalytic processes involving $\mathrm{CO}$ activation and fixation to organic moieties. In some cases, a simple protonation can release the expected aldehyde as happens with tetracarbonyl acylferrates deriving from acylation of Collman's reagent [1]. In other cases, however, the intermediate hydroxycarbene complex [2] is stable enough to be the product of the protonation.

$\mathrm{Cp}(\mathrm{CO})_{2} \mathrm{Fe}(\mathrm{COR})+\mathrm{H}^{+} \rightarrow\left[\mathrm{Cp}(\mathrm{CO})_{2} \mathrm{Fe}=\mathrm{CR}(\mathrm{OH})\right]^{+}$

Since the compounds bearing the dicarbonyl cyclopentadienyliron unit are among the most extensively used in preparative chemistry [3], various hydrides have been tested as possible hydrogenolysis reagents. $\mathrm{LiAlH}_{4}$ and related derivatives reacted with one of the terminal CO ligands [4]; more covalent hydrogen transfer reagents, such as hydrogen, silicon or tin hydrides have then been considered to achieve the reductive cleavage of the metal acyl bond. Upon thermal or photochemical activation, trimethylsilane or stannane did cleave the metal carbon bond, but the silyl or stannyl derivative of the alcohol was formed simultaneously, together with bi or tri nuclear mixed organometallics [5]:

$$
\begin{aligned}
& \mathrm{Cp}(\mathrm{CO})_{2} \mathrm{Fe}(\mathrm{COR})+\mathrm{HMMe}_{3} \\
& \rightarrow \mathrm{RCH}_{2} \mathrm{OMMe}_{3}+\mathrm{Cp}(\mathrm{CO})_{2} \mathrm{Fe}(\mathrm{H})\left(\mathrm{MMe}_{3}\right)_{2} \\
& \quad \text { or } \mathrm{Cp}(\mathrm{CO})_{2} \mathrm{FeMMe}_{3} \quad \mathrm{M}=\mathrm{Si} \text { or } \mathrm{Sn}
\end{aligned}
$$

The best conditions for a selective formation of the aldehyde was trimethyltin hydride under photochemical inducement [6].

Because of the practical importance of this reaction in catalysis, and also because of the analogy between photochemical and electron transfer activation in terms of labilization of a coordination shell [7], we decided to explore the possibility of an electrochemical inducement of the reductive cleavage of the acyl metal bond by tin hydride, and the mechanism thereof. 


\section{Electrochemical investigation}

\section{Voltammetric methods}

At room temperature, the cyclic voltammogram of $\mathrm{Cp}(\mathrm{CO})_{2} \mathrm{Fe}(\mathrm{COR})$ in THF consists in a fully chemically reversible reduction wave, at a potential scan rate of 1 $\mathrm{V} \mathrm{s}^{-1}$ or above. This wave was shown to be monoelectronic, with a standard potential $E^{0}$ being $-1.83 \mathrm{~V}$ versus $\mathrm{SCE}$ when $\mathrm{R}=\mathrm{Me}$, and $-1.80 \mathrm{~V}$ when $\mathrm{R}=$ $\mathrm{CH}_{2} \mathrm{CH}_{2} \mathrm{Ph}$. At lower scan rates, the ratio $i^{\text {ox }} / i^{\text {red }}$ gradually becomes smaller than unity. This is clearly indicative that the so-formed anion $\left[\mathrm{Cp}(\mathrm{CO})_{2} \mathrm{Fe}(\mathrm{COR})\right]^{-}$has a half lifetime of a few tenths of a second at a millimolar concentration. Some $\mathrm{CpFe}(\mathrm{CO})_{2}^{-}$anion, the oxidation of which is visible at $-0.90 \mathrm{~V}$, is formed upon decomposition of the initial paramagnetic anion, see Fig. 1a.

When the same cyclic voltammetry experiment was run in the presence of one molar equivalent of tributyltin hydride, the voltammogram was drastically modified. At $0.5 \mathrm{~V} \mathrm{~s}^{-1}$, the reduction wave corresponding to the formation of the anionic complex $\left[\mathrm{Cp}(\mathrm{CO})_{2} \mathrm{Fe}(\mathrm{COR})\right]^{-}$dropped to approximately $30 \%$ of its previous size and also became chemically irre-
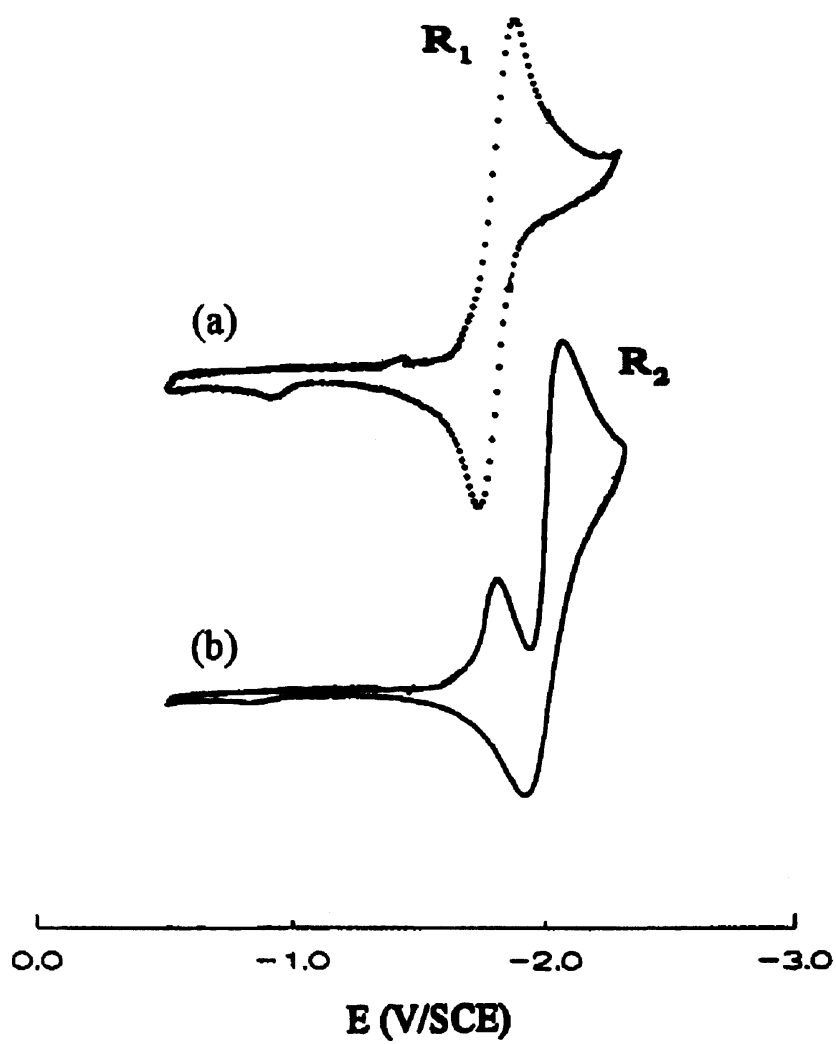

Fig. 1. Cyclic voltammetry of $\mathrm{Cp}(\mathrm{CO})_{2} \mathrm{Fe}\left(\mathrm{COCH}_{3}\right), 2 \mathrm{mM}$ solution in $\mathrm{THF} / 0.3 \mathrm{M}^{n} \mathrm{Bu}_{4} \mathrm{BF}_{4}$ at a gold electrode $(0.5 \mathrm{~mm}$ diameter); potential scan rate $0.5 \mathrm{~V} \mathrm{~s}^{-1}$. Curve (a) complex alone; curve (b) in the presence of 1 molar equivalent of $\mathrm{Bu}_{3} \mathrm{SnH}$.

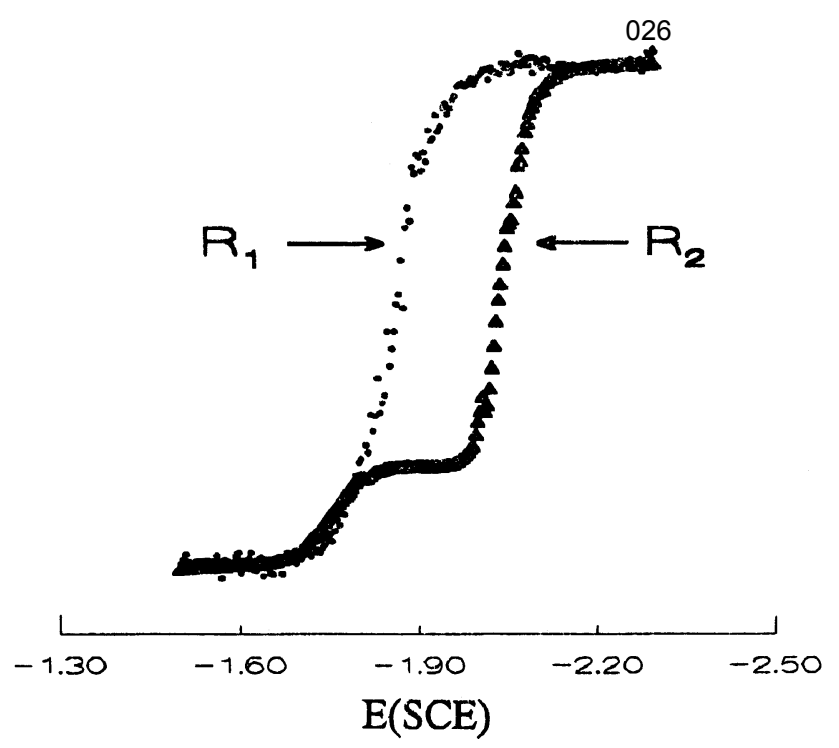

Fig. 2. Steady-state voltammogram of $\mathrm{Cp}(\mathrm{CO})_{2} \mathrm{Fe}\left(\mathrm{COCH}_{2} \mathrm{CH}_{2} \mathrm{Ph}\right), 2$ $\mathrm{mM}$ solution in $\mathrm{THF} / 0.3 \mathrm{M}^{n} \mathrm{Bu}_{4} \mathrm{BF}_{4}$ at a gold electrode $(25 \mu \mathrm{m}$ diameter); potential scan rate $10 \mathrm{mV} \mathrm{s}^{-1}$. $\bullet$, complex alone; $\boldsymbol{\Delta}$, in the presence of 5 molar equivalents of $\mathrm{Bu}_{3} \mathrm{SnH}$.

versible, see Fig. 1b. The oxidation wave at $-0.90 \mathrm{~V}$ also disappeared showing that $\mathrm{CpFe}(\mathrm{CO})_{2}^{-}$was no longer formed in the diffusion layer. Simultaneously, a new wave appeared at a slightly more negative potential, the size of which was close to the size of the reduction wave of the acyl complex in the absence of tin hydride. This new wave is chemically reversible, located at a standard potential $E^{0}=-2.02 \mathrm{~V}$, and could be assigned to the reduction of the heterobinuclear complex $\mathrm{Cp}(\mathrm{CO})_{2} \mathrm{FeSnBu}_{3}$ by comparison with cyclic voltammograms of an authentic sample of this latter compound [8].

Steady state voltammograms obtained at a small microelectrode $(\varnothing 25 \mu \mathrm{m})$ and very slow potential scan rate $\left(10 \mathrm{mV} \mathrm{s}^{-1}\right)$ are perhaps better suited to illustrate the phenomenon: an important decrease of the current corresponding to the reduction of the acyl complex in the presence of tin hydride, together with the apparition of a new wave and the conservation of the overall reduction current; compare the two waves in the presence and absence of $\mathrm{Bu}_{3} \mathrm{SnH}$ in Fig. 2.

Increasing the amount of tributyltin hydride at the same potential scan rate just made the observations depicted above still more visible, i.e. led to a more pronounced decrease of the size of the first reduction wave. This indicates that the overall process is controlled by a bimolecular step involving $\left[\mathrm{Cp}(\mathrm{CO})_{2} \mathrm{Fe}(\mathrm{COR})\right]^{-}$and $\mathrm{Bu}_{3} \mathrm{SnH}$. Conversely, increasing the potential scan rate for a given excess of tin hydride progressively restored the initial voltammetric pattern. Fig. 3 illustrates that it is necessary to reach $200 \mathrm{~V} \mathrm{~s}^{-1}$ at minimum to 'freeze' the kinetics of the chemical process when a ten molar equivalent excess of 

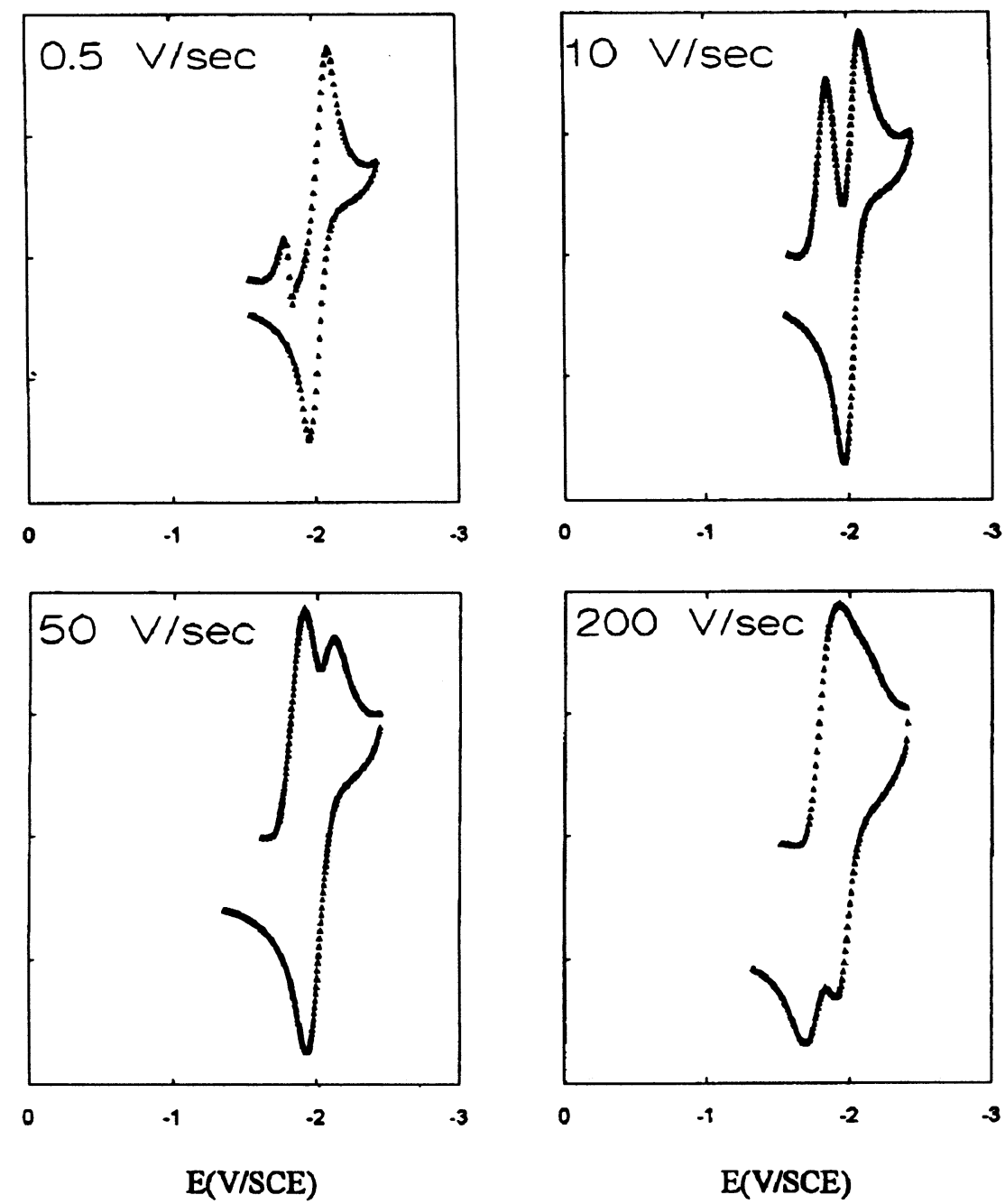

Fig. 3. Cyclic voltammograms of $\mathrm{Cp}(\mathrm{CO})_{2} \mathrm{Fe}\left(\mathrm{COCH}_{2} \mathrm{CH}_{2} \mathrm{Ph}\right), 3 \mathrm{mM}$ solution in $\mathrm{THF} / 0.3 \mathrm{M}^{n} \mathrm{Bu}_{4} \mathrm{BF}_{4}$ in the presence of ten molar equivalents of $\mathrm{Bu}_{3} \mathrm{SnH}$, at a gold electrode $(0.5 \mathrm{~mm}$ diameter $)$ and various potential scan rates.

tributyltin hydride is used. It is also noteworthy that the first reduction wave remains fully irreversible even at a potential scan rate $\left(50 \mathrm{~V} \mathrm{~s}^{-1}\right)$ where most of its initial size has been regenerated.

All these observations establish that a very fast reaction between the reduced form of the initial acyliron and tributyltin hydride takes place in the diffusion layer. The strong decrease of the size of the reduction wave $R_{1}$ points to a process where the electron initially used to reduce the acyl complex is given back to the system at the end of the reaction scheme, in other words, that the electron acts as a catalyst [9].

\section{Identification of the products formed; preparative aspects}

The organometallic product of the reaction could be identified from its reversible reduction wave as the heterobinuclear complex $\mathrm{Cp}(\mathrm{CO})_{2} \mathrm{FeSnBu}_{3}$. Further confirmation of this assignment was obtained by in- frared spectroscopy. Indeed, a solution of $\mathrm{Cp}(\mathrm{CO})_{2} \mathrm{Fe}\left(\mathrm{COCH}_{2} \mathrm{CH}_{2} \mathrm{Ph}\right)$ in THF was electrolyzed at $-1.8 \mathrm{~V}$ in the presence of 5 molar equivalents of tributyltin hydride, and the course of the reaction was monitored by recording IR spectra of aliquots. As the electrolysis proceeded, the three characteristic absorption bands of the starting acyliron complex, two bands at 2016 and $1956 \mathrm{~cm}^{-1}$ for the two coordinated CO and one at $1648 \mathrm{~cm}^{-1}$ for the carbonyl of the acyl group [10] progressively decreased, and three new waves appeared concomitantly; two of them, in the CO region at 1980 and $1929 \mathrm{~cm}^{-1}$, corresponded to $\mathrm{Cp}(\mathrm{CO})_{2} \mathrm{FeSnBu}_{3}$ [8], and the third and weaker one, at $1724 \mathrm{~cm}^{-1}$ could easily be assigned to dihydrocinnamaldehyde. At the end of the electrolysis, a yield of aldehyde in the range of $60-70 \%$ could be estimated from the intensity of the absorption at $1724 \mathrm{~cm}^{-1}$ but this determination lacked of accuracy because of the small value of the extinction coefficient of the aldehyde (about six to seven times smaller than the $\varepsilon$ of the 
carbonyl ligands). This yield was, however, confirmed by $\mathrm{GC}$ analysis.

The complete conversion of the acyl iron complex and subsequent formation of the two products in good to high yield were achieved when only 0.25 Faradays per mole of starting complex were passed through the solution, in agreement with an electron transfer catalysed process.

\section{The chain reaction process}

In voltammetric experiments, the drop in the size of the reduction wave of $\mathrm{Cp}(\mathrm{CO})_{2} \mathrm{Fe}(\mathrm{COR})$ when tin hydride is added indicates that a chemical process initiated on the foot of this reduction wave, i.e. when a small amount of reduced anionic complex is generated in the diffusion layer, consumes most of the starting acyliron during the time needed to scan over this wave. This behaviour which corresponds to an electron transfer catalysed process has been recognised in many ligand exchange reactions and reviewed [11]. A homogeneous intermolecular electron transfer from the reduced form of one of the products (here the heterobinuclear complex) to the starting material (Eq. (1) below) is responsible for the propagation of the chain reaction in the diffusion layer, see Scheme 1. When the potential of the electrode now reaches the reduction potential of this heterobinuclear compound, the latter is stoichiometrically reduced, as shown by the one electron reversible reduction wave $R_{2}$.

At the first reduction wave $R_{1}$ (zero electron at a sufficiently long time scale):

$\left[\mathrm{Cp}(\mathrm{CO})_{2} \mathrm{Fe}(\mathrm{COR})\right]^{-}+\mathrm{Bu}_{3} \mathrm{SnH}$

$\rightarrow\left[\mathrm{Cp}(\mathrm{CO})_{2} \mathrm{FeSnBu}_{3}\right]^{-}+\mathrm{RCHO}$

$\left[\mathrm{Cp}(\mathrm{CO})_{2} \mathrm{FeSnBu}_{3}\right]^{-}+\mathrm{Cp}(\mathrm{CO})_{2} \mathrm{Fe}(\mathrm{COR})$

$\rightarrow\left[\mathrm{Cp}(\mathrm{CO})_{2} \mathrm{FeSnBu}_{3}\right]+\left[\mathrm{Cp}(\mathrm{CO})_{2} \mathrm{Fe}(\mathrm{COR})\right]^{-}$

At the second reduction wave $R_{2}$ (one electron):

$\left[\mathrm{Cp}(\mathrm{CO})_{2} \mathrm{FeSnBu}_{3}\right]+\mathrm{e} \rightarrow\left[\mathrm{Cp}(\mathrm{CO})_{2} \mathrm{FeSnBu}_{3}\right]^{-}$

\section{$\mathrm{Cp}(\mathrm{CO})_{2} \mathrm{FeCOR}$}
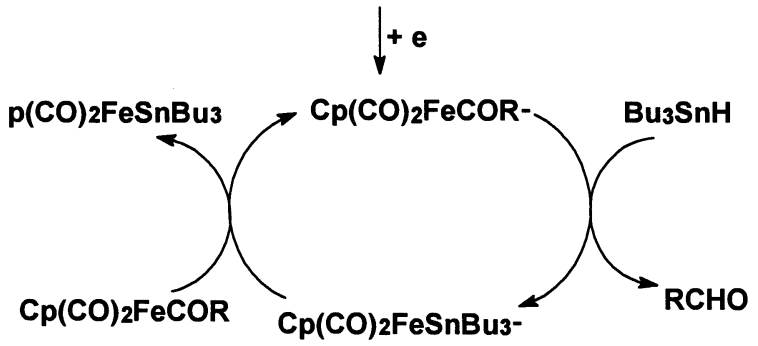

Scheme 1
During the preparative electrolysis, a controlled flow of electrogenerated acyl iron anions diffuse from the electrode to the bulk of the solution where the homogeneous process represented in Scheme 1 takes place. Unidentified termination reactions lead to a decrease of the catalytic efficiency by deactivation of the chain. These are more efficient in preparative scale electrolyses (where the turn-over is $\sim 4$ ) than under the conditions of voltammetry experiments [12]. Because of these termination reactions, it was necessary to maintain a small current flowing during the whole electrolyses; an interruption of the current leads to an interruption of the reaction.

The second step (Eq. (2)) of the propagation is controlled by the difference $\Delta E^{0}$ between the standard potentials of the two redox couples; since the standard potential of the binuclear product is more negative than that of the starting compound, it is exergonic and therefore very fast [13]. The first step (Eq. (1)) is expected to be rate determining.

A quantitative study of the kinetics is the object of current investigations. However the time scale in which this reaction takes place, as illustrated by the series of voltammograms in Fig. 3, shows that the reaction of $\left[\mathrm{Cp}(\mathrm{CO})_{2} \mathrm{Fe}(\mathrm{COR})\right]^{-}$with 5 molar equivalents of tributyl tin hydride (in a $10 \mathrm{mmol}$ range concentration) is at least 100 times faster that the spontaneous decomposition of this anion. This fact rules out any possibility of SN1-type reaction involving a partial decoordination or cleavage of this anion prior to its reaction with the tin hydride.

\section{Conclusion}

Cyclopentadienyl dicarbonyl acyliron compounds are rather inert toward trialkyltin hydride in standard conditions. However, a very fast hydrogenolysis leading to the corresponding aldehyde takes place when a small fraction of the acyliron complex is reduced to its radical anion by electron transfer. The overall kinetics of this chain process are controlled by a bimolecular reaction between this electrogenerated anion and the tin hydride. Since these acyl iron complexes are very easily prepared by acylation of $\mathrm{Cp}(\mathrm{CO})_{2} \mathrm{Fe}^{-}$this new reaction can be seen as an indirect but chimioselective reduction of acyl chlorides $\mathrm{RCOCl}$ into aldehydes.

\section{Acknowledgements}

This work was supported by the CNRS (URA 1679) and the Ecole Normale Supérieure. The authors wish to express their gratitude to Dr L. Pospisil and Dr J. Fiedler (J. Heyrovsky Institute of Physical Chemistry, Prague, Czech Republic) for stimulating discussions; 
indeed, this preliminary work is further developed with them as part of a European COST project D5/008/94.

\section{References}

[1] J.P. Collman, Acc. Chem. Res. 8 (1975) 342.

[2] (a) M.L.H. Green, C.R. Hurley, J. Organomet. Chem. 10 (1967) 188. (b) B.E. Boland-Lussier, M.R. Churchill, R.P. Hughes, Organometallics 1 (1982) 628.

[3] S.G. Davies, Organotransition Metal Chemistry: Applications to Organic Synthesis, Pergamon Press, Oxford, 1982.

[4] A. Wong, J.D. Atwood, J. Organomet. Chem. 210 (1981) 395.

[5] M. Akita, T. Oku, Y. Moro-oka, J. Chem. Soc., Chem. Commun. (1989) 1790.

[6] M. Akita, T. Oku, M. Tanaka, Y. Moro-oka, Organometallics 10 (1991) 3080

[7] (a) W.C. Trogler, in: Organometallic Radical Processes, J. Organometallic Chemistry Library 22, Elsevier, Amsterdam, 1990. (b) M. Chanon, M. Julliard, J.C. Poite (Eds.), Paramagnetic Organometallic Species in Activation, Selectivity and Catalysis, Kluwer, Dordrecht, 1989.

[8] B.A. Goodman, R. Greatrex, N.N. Greenwood, J. Chem. Soc.
(A) (1971) 1868

[9] It is not unprecedented in this series of compounds; the related alkyliron complex $\mathrm{Cp}(\mathrm{CO})_{2} \mathrm{FeR}$ undergoes an electron transfer catalysed carbonylation in the presence of extra ligand; the migration-insertion of $\mathrm{CO}$ can be induced either by oxidation, see (a) R.H. Magnuson, R. Meirowitz, S.J. Zulu, W.P. Giering, Organometallics 2 (1983) 460, or by reduction see (b) D. Miholova, A. Vlcek, J. Organomet. Chem. 240 (1982) 413. (c) C. Amatore, M. Bayachou, J.N. Verpeaux, L. Pospisil, J. Fiedler, J. Electroanal. Chem. 387 (1995) 101.

[10] R.B. King, J. Am. Chem. Soc. 85 (1963) 1918.

[11] For an early and pioneer example, see (a) R.L. Rich, H. Taube, J. Am. Chem. Soc. 76 (1954) 2608. For reviews see (b) J.K. Kochi, J. Organomet. Chem. 300 (1986) 139. (c) M. Chanon, Acc. Chem. Res. 20 (1987) 214. (d) D. Astruc, Angew. Chem. Int. Ed. Engl. 27 (1988) 643. (e) D. Astruc in Electron transfer and radical processes in transition-metal chemistry, $\mathrm{VCH}$, NewYork, 1995.

[12] For a related example of an electron transfer catalysed reaction on an iron centre where the efficiency is very different upon voltammetric and preparative conditions, see the last reference quoted in Ref. [9].

[13] C. Amatore, in: W.C. Trogler (Ed.), Organometallic Radical Processes, J. Organometallic Chemistry Library 22, Ch. 1, Elsevier, Amsterdam, 1990, pp. 1-48. 